\title{
Management of Sudden Sensorineural Hearing Loss: Our Experience
}

\author{
Ratna Priya, Junaid Malik*, Seema Monga, Shahid Rasool, Humra Shamim and Khaja Naseeruddin \\ Department of ENT HAH Centenary Hospital and Hamdard Institute of medical Sciences and Research, India
}

Submission: January 21, 2019; Published: January 31, 2019

*Corresponding author: Junaid Malik, Department of ENT HAH Centenary Hospital and Hamdard Institute of medical Sciences and Research, India

\section{Introduction}

Idiopathic sudden sensorineural hearing loss (SNHL) is described in literature as sudden onset of hearing loss occurring in a time period of around 3 days or even less that is likely to affect three or more frequencies by $30 \mathrm{~dB}$ or greater with no recognized cause [1]. The condition is usually expected to involve one ear and routinely patients do have accompanying complaints of tinnitus and aural fullness. The incidence is somewhat around 5 and 20 persons per 100,000 year [2]. The actual incidence of sudden sensorineural hearing loss is apparently set too low as a good amount of such patients do have spontaneous recovery and are doubtful to come upon for medical help.

\section{Material and Methods}

Our series consists of prospective study of patients who presented to the department of ENT and head and neck surgery of HAHC Hospital, Jamia Hamdard, New Delhi between January 2017 and September 2018. Here, the candidates were advised intratympanic dexamethasone for sudden sensorineural hearing loss. All our patients underwent full work up and the investigations included hemogram, ESR and MRI Brain to rule out possibility of cerebropontine angle tumors. Hearing was assessed using pure tone audiometry (PTA). All candidates who developed sudden sensorineural hearing loss in less than 3 days to up to 6 weeks were included in the study. They received high dose prednisolone $1 \mathrm{mg} / \mathrm{kg}$ for 5 days followed by tapering doses. Intratympanic dexamethasone was given weekly starting from first week along with oral prednisolone. $0.4 \mathrm{ml}$ of dexamethasone $(24 \mathrm{mg} / \mathrm{ml})$ injection was given weekly for up to 6 weeks. Pre and post procedure audiogram were performed and improvement in hearing was recorded. Severity of hearing loss was graded as: Mild: (26-40 dB), Moderate: (41-55 dB), Moderately severe: (56-70 dB), Severe: (71-90 dB) and Profound: (>90 dB).

The magnitude of improvement in hearing was analyzed as per widely prevalent Wilson's criteria which are as follows:

i. Complete Recovery is post-treatment PTA within $10 \mathrm{~dB}$ of baseline audiogram. ii. Partial Recovery if post-treatment PTA is within 50\% of initial hearing level or $>10 \mathrm{~dB}$ improvement in hearing.

iii. No Recovery is a $<10 \mathrm{~dB}$ [1]. The statistical test used was paired T test.

\section{Results}

Table 1: Age Distribution.

\begin{tabular}{|c|c|c|}
\hline Age (in years) & No. Of cases & Percentage (N = 16) \\
\hline $10-20$ & 3 & $19 \%$ \\
\hline $20-30$ & 2 & $12 \%$ \\
\hline $30-40$ & 3 & $19 \%$ \\
\hline $40-50$ & 5 & $31 \%$ \\
\hline $50-60$ & 3 & $19 \%$ \\
\hline
\end{tabular}

Table 2: Sex distribution.

\begin{tabular}{|c|c|c|}
\hline Sex & $\begin{array}{c}\text { Number of } \\
\text { cases }\end{array}$ & $\begin{array}{c}\text { Percentage (Total number of } \\
\text { cases =16) }\end{array}$ \\
\hline Male & 6 & $38 \%$ \\
\hline Female & 10 & $62 \%$ \\
\hline
\end{tabular}

Table 3: Distribution of cases of Sudden SNHL according to sides.

\begin{tabular}{|c|c|c|}
\hline Side & $\begin{array}{c}\text { Number of } \\
\text { cases }\end{array}$ & $\begin{array}{c}\text { Percentage (Total Number } \\
\text { of cases = 16) }\end{array}$ \\
\hline Only Right sided & 6 & $38 \%$ \\
\hline Only Left sided & 10 & $62 \%$ \\
\hline Bilateral & None & \\
\hline
\end{tabular}

The mean age of patient was 36 years ranging from 15 to 60 years. We had 6 male and 10 female patients. 10 patients were suffering with left sided hearing loss and remaining 6 had right sided involvement. The mean time when the diagnosis was made was 5 days varying from 3 to 60 days. The average time to treatment was essentially the same as time to presentation. In our group, 5 patients had profound sensorineural hearing loss, 3 patients had moderately severe type of SNHL, 2 of the patients suffered from severe SNHL, 5 patients had moderate variety of SNHL and only one patient had mild SNHL. All the patients received a combined modality of treatment with oral 
steroids and intratympanic steroids. On analyzing the results, 7 out of 16 patients did show complete improvement following our treatment protocol. Also, 5 of our patients had partial recovery. However, 4 patients did not have any response to our treatment. Among the no response group of patients, the initial time of presentation to the hospital was more than 20 days in 3 patients. The average PTA before treatment was $57 \mathrm{~dB}$ and after treatment was $42.5 \mathrm{~dB}$ with an improvement of $14.5 \mathrm{~dB}$. The results of treatment were analyzed by means of paired $t$ test. $\mathrm{P}$ value came out to be 0.0002 which by convention is statistically significant (Tables 1-3).

\section{Discussion}

Table 4: Distribution of cases of Sudden SNHL with degree of hearing loss.

\begin{tabular}{|c|c|}
\hline Degree of Hearing loss & No. of cases $\mathbf{( N = 1 6 )}$ \\
\hline Mild(25-40dB) & 1 \\
\hline Moderate $(40-55 \mathrm{~dB})$ & 5 \\
\hline Mod-severe $(55-70 \mathrm{~B})$ & 3 \\
\hline $\begin{array}{c}\text { Severe } \\
(70-90 \mathrm{~dB})\end{array}$ & 2 \\
\hline $\begin{array}{c}\text { Profound } \\
(>90 \mathrm{~dB})\end{array}$ & 5 \\
\hline
\end{tabular}

The literature suggests that sudden sensorineural hearing loss can occur as a result of varied causes such as viral infection, microvascular disturbance and autoimmune conditions $[3,4]$. It is said that up to $65 \%$ of the total patients will be better without any treatment within 15 days of sudden hearing loss Table 5: Treatment Results.
[5]. The usual treatment options are steroids along with antiviral agents, vasodilators and hyperbaric oxygen therapy [6]. The monumental trial given by Wilson et al in 1980 did prove high dose oral or intravenous steroids as the first line of management in sudden SNHL [7]. The initial description of the use of intratympanic steroids as a part of treatment protocol of sudden SNHL was presented in 1996 by Silverstin. His study comprised of 8 patients, out of which 2 patients has adequate recovery. Following this a number of studies have come up with treatment of idiopathic sudden SNHL with intratympanic steroids, especially in patients who do not benefit from high dose oral or intravenous steroids, intratympanic dexamethasone works as a salvage therapy [8]. In publications by Roebuck and Chang, intratympanic dexamethasone injections show improvement in $39 \%$ of patients with a pure tone average (PTA) improvement of $12 \mathrm{Db}$, versus $10 \%$ and $10 \mathrm{~dB}$ in the control group [9]. Plaza and Herráiz studied that $55 \%$ of patients had improvement after IT steroid injections with an average PTA improvement of $33 \mathrm{~dB}$, versus $0 \%$ and $12 \mathrm{~dB}$, respectively, in those patients who refused therapy [10]. In patients with diabetes mellitus, IT steroid injections notably improved hearing in $70 \%$ of cases with a mean PTA improvement of $41 \mathrm{~dB}$, versus $67 \%$ and $25 \mathrm{~dB}$, respectively, in patients who received intravenous dexamethasone [11]. Nowadays, as result, a lot of physicians do consider intratympanic steroids as first line treatment in option in patients with idiopathic sudden SNHL. In our study, the average PTA before treatment was $57 \mathrm{~dB}$ and after treatment was $42.5 \mathrm{~dB}$ with an improvement of $14.5 \mathrm{~dB}$ (Tables 4-6).

\begin{tabular}{|c|c|c|c|c|c|c|c|c|}
\hline S No & $\begin{array}{l}\text { Duration In days } \\
\text { (of presentation) }\end{array}$ & Pre AC (IN dB) & Post AC (IN dB) & Pre BC & Post BC (in dB) & $\begin{array}{l}\text { Pre AB GAP } \\
\text { (IN dB) }\end{array}$ & Post AB Gap & Improvement \\
\hline 1 & 3 & 110 & 40 & 50 & 30 & 60 & 10 & $\mathrm{P}$ \\
\hline 2 & 4 & 110 & 50 & 70 & 35 & 40 & 15 & $\mathrm{C}$ \\
\hline 3 & 3 & 41 & 30 & 35 & 25 & 6 & 5 & $\mathrm{C}$ \\
\hline 4 & 5 & 30 & 22 & 25 & 17 & 5 & 5 & $\mathrm{C}$ \\
\hline 5 & 5 & 90 & 55 & 70 & 50 & 20 & 5 & $\mathrm{P}$ \\
\hline 6 & 4 & 82 & 69 & 72 & 59 & 10 & 10 & $\mathrm{P}$ \\
\hline 7 & 3 & 75 & 35 & 65 & 25 & 10 & 10 & $\mathrm{C}$ \\
\hline 8 & 5 & 55 & 35 & 35 & 30 & 20 & 5 & $\mathrm{C}$ \\
\hline 9 & 5 & 98 & 50 & 58 & $40 / 30$ & 40 & 10 & $\mathrm{C}$ \\
\hline 10 & 3 & 57 & 45 & 37 & 30 & 27 & 15 & $\mathrm{C}$ \\
\hline 11. & 3 & 80 & 70 & 75 & 65 & 5 & 5 & $\mathrm{~N}$ \\
\hline 12 & 60 & 110 & 110 & 80 & 80 & & & $\mathrm{~N}$ \\
\hline 13 & 5 & 65 & 50 & 50 & 35 & 15 & 15 & $\mathrm{P}$ \\
\hline 14 & 20 & 60 & 55 & 55 & 50 & 5 & 5 & $\mathrm{~N}$ \\
\hline 15 & 30 & 90 & 90 & 70 & 70 & 20 & 20 & $\mathrm{~N}$ \\
\hline 16 & 4 & 70 & 55 & 65 & 50 & 15 & 15 & $\mathrm{P}$ \\
\hline
\end{tabular}

Intratympanic dexamethasone is given direction via injection through the tympanic membrane and reaches the round window membrane to have an effect on inner ear. The chance of systemic absorption is minimal; hence it is a good option for those who are unable to take systemic steroids. The usual side effects of intratympanic therapy consist of persistent tympanic membrane 
perforations, short duration vertigo, tinnitus and otitis media. The patients are supposed to keep their heads in a particular position for 15 to 20 minutes, so that round window gets optimal steroid exposure and loss of drug via Eustachian tube can be minimized. Another point to consider are the anatomical barriers which obstruct drug from reaching round window that affects final outcome. One of the study states that round window membrane in about one third of temporal bones may be blocked by a pseudo-membrane, fibrous tissue or a fat plug [12]. Time of initiation of treatment is an important factor to consider before starting steroids as maximal benefit is seen with 2 weeks of onset of hearing loss. In our study, no benefit is seen in patients who presented after 20 days of hearing loss.

Table 6: Recovery following treatment.

\begin{tabular}{|c|c|c|}
\hline Treatment Effect & No of cases & Percentage (N= 16) \\
\hline Complete recovery & 7 & 44 \\
\hline Partial recovery & 5 & 31 \\
\hline No recovery & 4 & 25 \\
\hline
\end{tabular}

\section{Conclusion}

Intratympanic dexamethasone treatment as first line of management for sudden sensorineural hearing loss seems to be parallel to treatment with high-dose oral prednisone therapy. As rescue therapy, intratympanic steroids have some amount of additional hearing improvement. Also, intratympanic drug treatment benefits by improving drug concentrations in inner ear with minimal systemic effects. Also, we would like to emphasize that sudden deafness should be treated as a medical emergency and prompt treatment as early as possible does effect treatment outcome.

\section{References}

1. Wilson WR, Byl FM, Laird N (1980) The efficacy of steroids in the treatment of idiopathic sudden hearing loss. A double blind clinical study. Arch Otolaryngol 106(12): 772-776.
2. Byl FM (1984) Sudden hearing loss: eight years' experience and suggested prognostic table. Laryngoscope 94(5 Pt 1): 647-661.

3. AF Deroee, TC Huang, N Morita (2009) Sudden hearing loss as the presenting symptom of systemic sclerosis Otol Neurotol 30(3): 277293.

4. D Yehudai, Y Shoenfeld, E Toubi (2006) The autoimmune characteristics of progressive or sudden sensorineural hearing loss. Autoimmunity 39(2): 153-158

5. Mattox DE, Simmons FB (1997) Natural history of sudden sensorineural hearing loss. Ann Otol 86: 463-480.

6. Slattery WH, Fisher LM, Iqbal Z, Friedman RA, Liu N (2005) Intratympanic steroid injection for treatment of idiopathic sudden hearing loss. Otolaryngol Head Neck Surg 133(2): 251-259.

7. Wilson WR, Byl FM, Laird N (1980) The efficacy of steroids in the treatment of idiopathic sudden hearing loss: a double-blind clinical study. Arch Otolaryngol 106(12): 772-776.

8. Silverstein H, Choo D, Rosenberg SI, Kuhn J, Seidman M, Stein I (1996) Intratympanic steroid treatment of inner ear disease and tinnitus (preliminary report). Ear Nose Throat J 75(8): 468-471.

9. Roebuck J, Chang CY (2006) Efficacy of steroid injection on idiopathic sudden sensorineural hearing loss. Otolaryngol Head Neck Surg 135: 276-279.

10. Plaza G, Herráiz C (2007) Intratympanic steroids for treatment of sudden hearing loss after failure of intravenous therapy. Otolaryngol Head Neck 137(1): 74-78.

11. Kakehata S, Sasaki A, Oji K, Futai K, Ota S, et al. (2006) Comparison of intratympanic and intratympanic and intravenous dexamethasone treatment on sudden sensorial hearing loss with diabetes. Otol Neurotol 27: 604-608.

12. Alzamil KS, Linthicum FH (2000) Extraneous round window membranes and plugs: possible effect on intratympanic therapy. Ann Otol Rhinol Laryngol 109(1): 30-32.

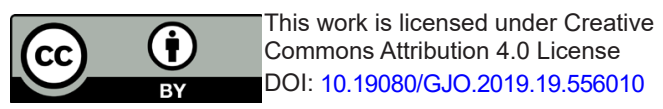

\begin{tabular}{l} 
Your next submission with Juniper Publishers \\
will reach you the below assets \\
- Quality Editorial service \\
- Swift Peer Review \\
- Reprints availability \\
- E-prints Service \\
- Manuscript Podcast for convenient understanding \\
- Global attainment for your research \\
- Manuscript accessibility in different formats \\
( Pdf, E-pub, Full Text, Audio) \\
- Unceasing customer service \\
Track the below URL for one-step submission \\
https://juniperpublishers.com/online-submission.php \\
\hline
\end{tabular}

